Int. J. Electrochem. Sci., 15 (2020) $8849-8872$

\title{
Thermodynamic Performance Evaluation on a Molten Hydroxide Direct Carbon Fuel Cell with Asymmetric Anode and Cathode
}

\author{
Yuan Han ${ }^{1}$, Houcheng Zhang ${ }^{1, *}$, Ziyang $\mathrm{Hu}^{1}$, Shujin $\mathrm{Hou}^{2, *}$ \\ ${ }^{1}$ Department of Microelectronic Science and Engineering, Ningbo University, Ningbo 315211, China \\ ${ }^{2}$ College of Physics and Electronic Engineering, Nanyang Normal University, Nanyang 473061, \\ China \\ *E-mail: zhanghoucheng@ nbu.edu.cn (H. Zhang); houshujingrb@163.com (S. Hou).
}

doi: $10.20964 / 2020.09 .64$

Received: 2 May 2020 / Accepted: 13 July 2020 / Published: 10 August 2020

The asymmetric electrode configuration can effectively solve the electrolyte carbonation problem for molten hydroxide direct carbon fuel cells (MHDCFCs), however, the thermodynamic performance of this kind of MHDCFC has not been well understood yet. Herein, an MHDCFC model with active carbon as fuel and molten sodium hydroxide $(\mathrm{NaOH})$ as electrolyte is proposed, in which the anode and cathode are asymmetric. According to the electrochemical reaction kinetics, electrode process and mass transfer, various irreversible losses of the electrochemical process are described. Considering diverse polarization losses, the thermodynamic performance of the MHDCFC is comprehensively evaluated by using output voltage, efficiency, power output, entropy production rate, ecological objective function and ecological coefficient of performance as objective functions. The MHDCFC model is validated to be reliable by comparing with previous modeling results. The generic performance characteristics of the MHDCFC are revealed. The effects of the operating temperature, anodic and cathodic chamber heights, fuel mass, $\mathrm{O}_{2}$ flow rate, cathodic pressure, and reaction chamber width on the MHDCFC performance are analyzed through exhaustive parametric studies. The obtained results may provide some insights into globally understanding the performance of MHDCFCs.

Keywords: Molten hydroxide direct carbon fuel cell; Efficiency; Power output; Ecology objective function; Ecological coefficient of performance

\section{$\underline{\text { FULL TEXT }}$}

(C) 2020 The Authors. Published by ESG (www.electrochemsci.org). This article is an open access article distributed under the terms and conditions of the Creative Commons Attribution license (http://creativecommons.org/licenses/by/4.0/). 